\title{
Proposed Procedure to Design an Optimum Ventilation System for Chemical Laboratory
}

\author{
Gara Idrees Abdoon1, Nagwa Fadl Bashir ${ }^{2 *}$ \\ ${ }^{1}$ Post Graduate Student, Department of Chemical Engineering, Faculty of Engineering, ALNeelain University, Khartoum, Sudan \\ ${ }^{2}$ Department of Chemical Engineering, Faculty of Engineering, ALNeelain University, Khartoum, Sudan \\ Email: ^fadlnagwa@yahoo.com, ^fadlnagwa@neelain.edu.sd
}

How to cite this paper: Abdoon, G.I. and Bashir, N.F. (2017) Proposed Procedure to Design an Optimum Ventilation System for Chemical Laboratory. Advances in Chemical Engineering and Science, 7, 325-332. https://doi.org/10.4236/aces.2017.73024

Received: February 13, 2017

Accepted: July 18, 2017

Published: July 21, 2017

Copyright ( 92017 by authors and Scientific Research Publishing Inc. This work is licensed under the Creative Commons Attribution International License (CC BY 4.0).

http://creativecommons.org/licenses/by/4.0/ (c) (i) Open Access

\begin{abstract}
The safe environmental condition of biological and chemical laboratories at universities in Sudan is a real and tangible problem that needs to be properly addressed due to the increased number of universities which grew up to 25 State-Level Universities. This could sum up to 200 students per academic year. One of the significant problems is the proper ventilation inside the laboratories. This paper aims to provide a proposal for design of an optimum ventilation system for: 1) Good and safe environment; 2) Comfortable workplace for laboratories occupants; 3) Ensure the health of the surrounding environment while minimizing the energy consumption. Five chemicals are selected for this study as the most consumed and the most hazardous (permissible exposure limits) inside the laboratories of the department of chemistry faculty of science, Al-Neelain university; formaldehyde, nitric acid, acetic acid, xylene and ethanol. Concentration level of materials in laboratory is calculated in correlation with air exchange rate, vapor pressure and area of laboratory. Results concluded to that up $15 \mathrm{ACH}$ the concentration of formaldehyde and nitric acid is still high. Recommendations are given with the limitation of using the suggested mathematical model, regarding laboratory conditions, severity of the material hazardousness, number of people.
\end{abstract}

\section{Keywords}

Laboratory Ventilation, Vapor Contamination, Air Changes Per Hour, PEL.ACH

\section{Introduction}

The laboratory ventilation system is designed to correct the laboratory environment.

All types of laboratories (chemical, biology, and microbiology) may generate pollution by harmful chemical gases and vapors. Particulates and biological agents, this pollution is processing by a correct ventilation system to remove this 
hazardous substance.

Proper ventilation of laboratory settings is required to promote and maintain laboratory safety and protection to life and property. Items such as fume containment, worker safety, and proper cleanliness through pressure relationships, filtration, and air changes per hour $(\mathrm{ACH})$, point of fume capture, temperature, and relative humidity requirements are elements necessary to design the ventilation system depending on the laboratory type.

The requirements listed below [1] [2] illustrate some of the basic health and safety design features required for new and remodeled laboratories. Variations from these guidelines require approval from the Environmental Health \& Safety Department (EH \& S):

1) Building Requirements:

- Professional designer.

- Type and quantities of chemicals material would be used to determine the final design.

- Environmental permits.

2) Laboratory Design Considerations:

- A process that integrates key decision makers (e.g., health and safety, users, facility operators) into the design team should be used.

- The laboratory shall be completely separated from outside areas (i.e., shall be bound by four walls and a roof or ceiling).

- Design of the laboratory and adjacent support spaces shall incorporate adequate additional facilities for the purpose of storage and/or the consumption of food, drinks, tobacco products, and the application of cosmetics.

- Mechanical climate control should be provided as needed.

- Laboratories should be designed with adequate workstation space, e.g., computers for instruments or data entry.

- Laboratory benches' standard depths are 30 inches for a wall bench, and 66 inches for an island bench. Bench lengths usually allow for 72 inches of free counter space per laboratory worker, in addition to the counter space allotted for equipment.

- Deskwork areas in laboratories shall be separate from areas where hazardous materials are used. Specifically, fume-hood openings shall not be located opposite desk-type work areas.

- Workstations in the laboratory need to accommodate computer monitors, keyboards, and work holders, and should have height adjustable work surfaces to minimize injuries from repetitive-motion stress.

- Ensure that casework has no vibration/ movement or loading limitations, is not seismic sensitive, interacts with laboratory equipment, is ergonomically designed, and is responsive to ADA concerns.

- Floor loading should be no more than $100-125$ pounds/in ${ }^{2}$. Heavy support

- Support columns should not be placed in open laboratory areas, but should be incorporated into lab benches, if possible.

- Avoid wet sprinklers in ductwork; avoid non-fireproof material in interstitial 
spaces.

- Locate eyewash/safety shower near door. Do not include a floor drain for the shower.

- Where hazardous, biohazardous, or radioactive materials are used, each laboratory shall contain a sink for hand washing. The sink drain shall be connected either to a retention tank or building plumbing.

- The lab bench shall be resistant to the chemical actions of chemicals and disinfectants.

- Design easy to clean.

- The walls will be nonporous and painted with a durable, impervious finish in such a manner to facilitate decontamination. High-gloss paint is recommended.

- Ports should be provided for obtaining samples of effluent from building laboratory drains.

- Vented cabinets with electrical receptacles and sound insulation should be provided for the placement of individual vacuum pumps, where their use is anticipated. A one- to two-inch hole for the vacuum line hose from the cabinet to the benchtop shall be provided.

- Laboratory areas should be well lit to avoid spills and other accidents that could result in contamination buildup.

\section{Previous Work Done}

- (O. A. Seppänen, et al; 1999), He reported that for $\mathrm{CO}_{2}$ [3], the ventilation leads relative risks of 1.5 - 2 for respiratory illnesses and 1.1 - 6 for sick building syndrome symptoms for low compared to high low ventilation rates.

- (Mingang Jin, Farhad Memarzadeh, Kisup Lee, and Qingyan Chen: 2012), are reported that for Experimental Study of Ventilation Performance in Laboratories with Chemical Spills [4], This experimental study investigated the ventilation performance under different ventilation rates in a chemistry laboratory mock-up. This investigation also studied the ventilation performance with and without the use of bench hood exhausts.

- (Robert C. Klein, Cathleen King \& Paula Castagna; 2013) [5], Controlling Formaldehyde Exposures in an Academic Gross Anatomy Laboratory, This report describes efforts over a more than a 15-year period to improve air quality and reduce exposures to formaldehyde during anatomical dissections at the Yale University School of Medicine, by installation of the ventilated tables.

\section{Methodology}

Proper ventilation in laboratories depend on knowing and measuring several units of measurement like humidity, air speed and pressure ratio within the laboratory and other rates of potential to reach perfect ventilation [6]. This proposal was based on the rate of change air inside the laboratory and its ability to dilute the concentration of the materials to PEL [7]. Calculations are carried for the concentration of the vapors in normal condition and when accident of spil- 
lage occurred. the results are compared to the PEL concentration. The experiments are carried out with these considerations:

- For laboratories of $100 \mathrm{~m}^{3}$ volume with an area of $1 \mathrm{~m}^{2}$ of spill chemical,

- With assumption of air velocity of $0.2 \mathrm{~m} / \mathrm{s}$,

- With average number of students per laboratory equal to 25,

- Only the most five consumed material are considered.

Chart 1 shows the percentage of the severity of the substances used inside chemistry laboratory in the faculty of science and technology.

In the table below is a list of selected materials most commonly used in university laboratories based on previous survey made by rated by severity to slightly hazardous (2), hazardous (3) and extremely hazardous (4) Table 1.

The calculations are based on heat-mass transfer analogy [8] applied to steady state conditions of a parallel flow over smooth liquid surface, at uniform liquid and air temperature. The mass flow rate $(\mathrm{kg} / \mathrm{s})$ from convective evaporation was determined by equation:

$$
m_{v}=h_{m} A_{v}\left(\rho_{v, s}-\rho_{v, \infty}\right)
$$

where $h_{m}(\mathrm{~m} / \mathrm{s})$ is the average mass transfer coefficient. $A_{V}\left(\mathrm{~m}^{2}\right)$ is the area of mass transfer, $\rho_{r, s}\left(\mathrm{~kg} / \mathrm{m}^{3}\right)$ is the vapor density at liquid-air interface and $\rho_{r, \infty}$ the vapor density in the free stream of air. $\rho_{v, \infty}$ may be considered negligible in re-

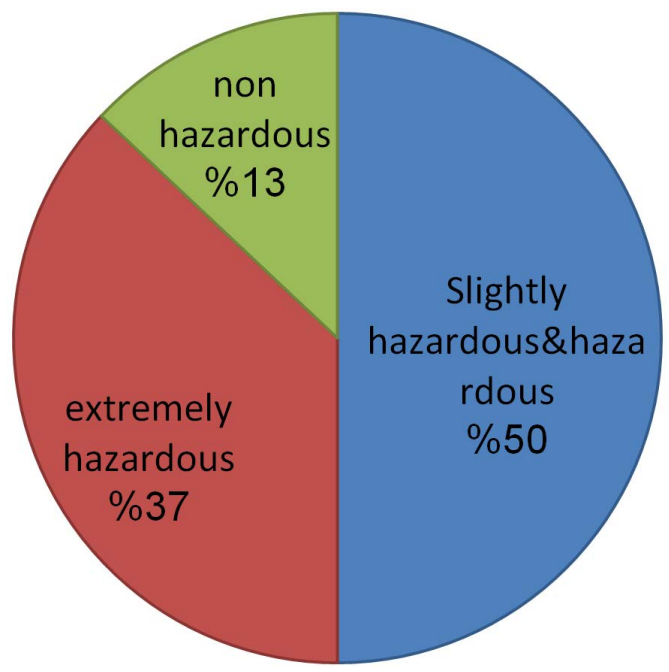

Chart 1. The percentage of hazardous materials according to the number of material comsummed.

Table 1. Severity of hazardous material and PEL for the five substances [9].

\begin{tabular}{ccc}
\hline Liquid & Severity of Health Hazard & PEL ppm \\
\hline Acetic acid & 2 & 15 \\
Formaldehyde & 4 & 1 \\
Xylene & 3 & 100 \\
Nitric acid & 4 & 2 \\
Ethanol & 2 & 1000 \\
\hline
\end{tabular}


spect to surface conditions and by approximating the vapor as perfect gas, Equation (1) can be expressed as:

$$
m_{v}=h_{m} A_{v} \frac{P_{v, s}}{R T}
$$

where $P_{V, s} \quad\left(\mathrm{~N} / \mathrm{m}^{2}\right)$ is the vapor pressure at liquid-air interface, $R$ is the specific gas constant in (J/kg.K) and $T$ is the air temperature in $(\mathrm{K})$.

The mass transfer coefficient was evaluated from heat and mass transfer analogy [8]

$$
h_{m}=\operatorname{Sh}\left(\frac{D_{v}}{L}\right)
$$

where $S h$ is the Sherwood number, $D_{V}\left(\mathrm{~m}^{2} / \mathrm{s}\right)$ is the diffusion coefficient of vapor into air, and $L(\mathrm{~m})$ the characteristic length of the mass transfer surface.

In all the applications analyzed below, a parallel flow over a flat plate was approximated. In all the cases, the flow resulted to be laminar $\left(R e=V L / v<5 \times 10^{5}\right)$, where $V$ is the free stream air velocity, and $v$ the kinematic viscosity. Sherwood number was evaluated by Equation (4)

$$
S h=0.664 R e^{1 / 2} S c^{1 / 3}(0.6<S c<50)
$$

Schmidt number $\left(S c=v / D_{v}\right)$ was calculated using $D_{v}$ values from CRC Handbook [10].

Volumetric concentration $C_{\text {v100 }}(\mathrm{ppm})$ was calculated

$$
C_{v 100}=\frac{\frac{m_{v}}{\rho_{v, s}}}{Q_{100}} \times 10^{6}
$$

where $Q_{100}\left(\mathrm{~m}^{3} / \mathrm{s}\right)$ is the air exchange rate in the $100 \mathrm{~m}^{3}$ volume.

Concentration level and adjusted air changes per hour in laboratory volumes $V_{L}$ other than $100 \mathrm{~m}^{3}$ can be evaluated as

$$
\begin{gathered}
C_{v L}=C_{v 100} \frac{V_{L}}{100} \\
A C H=\frac{100}{V_{L}} \times A C H_{100}
\end{gathered}
$$

\section{Result and Discussion}

Figure 1 shows the concentration of five substances used frequently in laboratory at 6,10 and 15 air changes per hour, resulted from evaporation of a $1 \mathrm{~m}^{2}$ spill in $100 \mathrm{~m}^{3}$ laboratory spaces.

The concentrations are compared with PEL concentrations. The results show that extremely hazardous chemicals, with PEL level of 5 or less, evaporate at a rate that substantially exceeds the permissible level for short time exposure, even diluted in $15 \mathrm{ACH}$ air flow. The substances less hazardous appear diluted to safe concentrations.

Figure 2 shows the number of air changes per hour required to bring the concentration of the evaporated liquid to the PEL limit. It could be noticed that 


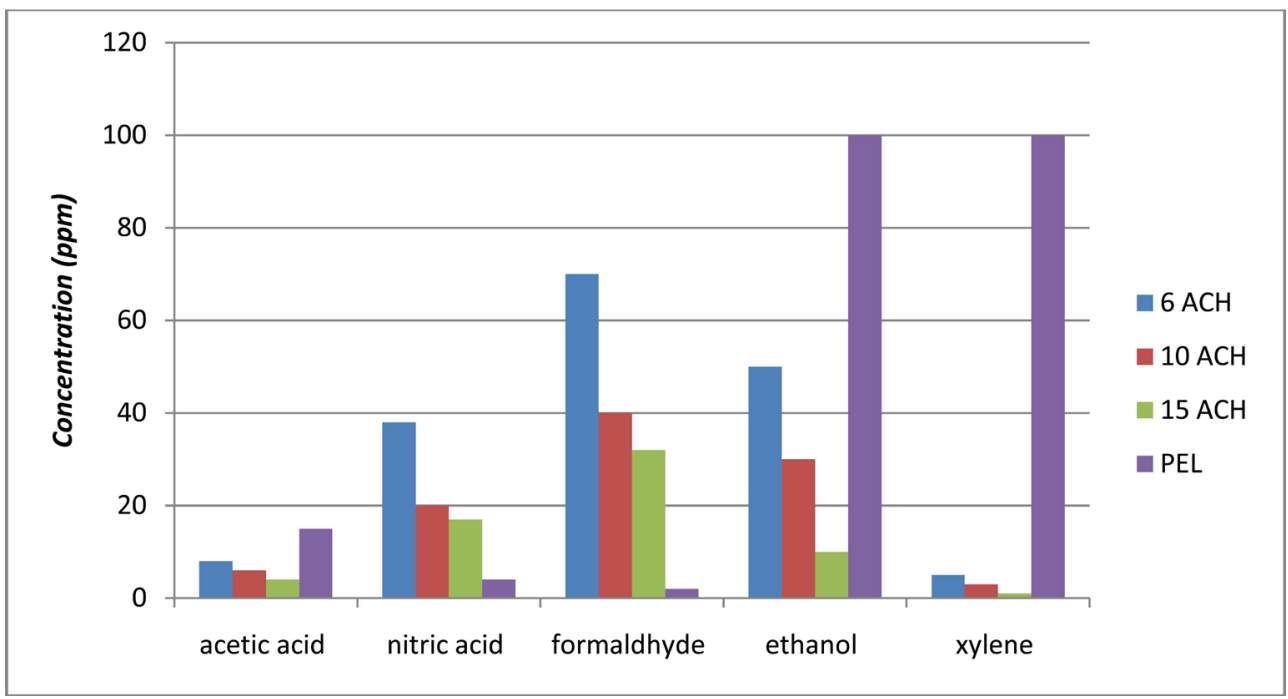

Figure 1. Concentration from evaporation of $1 \mathrm{~m}^{2}$ of liquid spill in $100 \mathrm{~m}^{3}$ space.

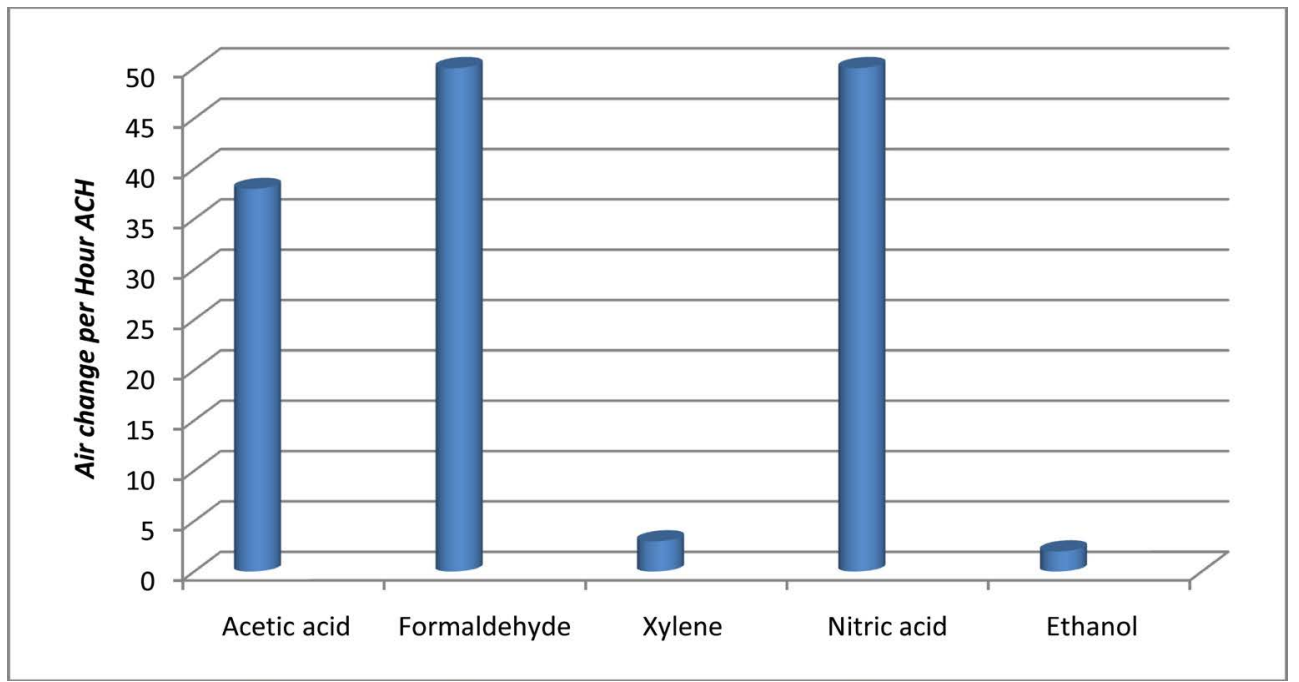

Figure 2. Air change per hour to reach PEL level in $100 \mathrm{~m}^{3}$.

that moderate and low hazardous substances can be safely diluted in air flow rates below $6 \mathrm{ACH}$.

The method of calculation using the above equations is fair indicator for the appropriate ventilation for the laboratory considered for this study.

Compared to the literature [3] [4] [5] the results obtained is considered satisfactory and relevant. For instance there is a study [7] where ethyl ether concentration is tested with range of 6 - 16 (Figure 3).

\section{Conclusions}

Through theoretical calculations of the concentrates of materials within the laboratory, based on mass transfer analogy assuming a constant air velocity 0.2 $\mathrm{m} / \mathrm{s}$, we have got a high dilute for slightly hazardous material affinity to PEL, whereas the extremely hazardous substances are still in high in concentrations above the allowable. If any additional ventilation like exhaust and central air 


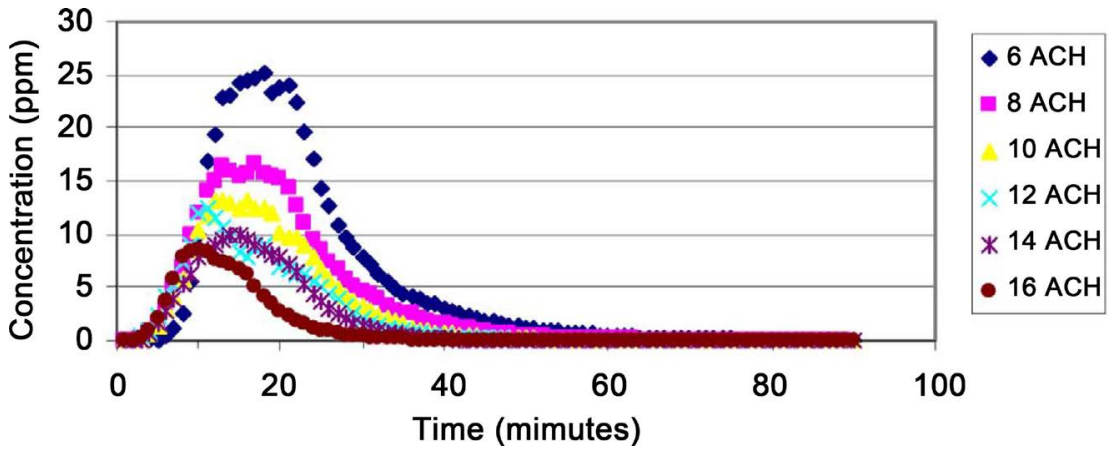

Figure 3. [10] Concentration of diethyl ether with ACH range 6 - 16.

condition unit was added inside the laboratory during experiments so that we increase the rate of air change and air velocity inside the laboratory to more than $0.2 \mathrm{~m} / \mathrm{s}$, we obtain to the affinity of acceptable optimum ventilation inside the laboratory to the limit the following is considered:

1) The standard number of person inside the laboratory.

2) The room temperature.

3) The severity of the hazardous chemical.

4) Excess ventilation may lead to loss of energy.

Therefore, due to difference in the operation condition, materials, and hazard level of a room change, an increase or decrease in the minimum ventilation rate should be evaluated for each. Furthermore for each experiment the appropriate ventilation rate should be calculated. It is also recommended that any airflow control must be integrated with the laboratory control system, and must not jeopardize the safety and function of the laboratory.

\section{References}

[1] General Requirements for Laboratories, Laboratory Safety Design Guide, September 2015. https://www.ehs.washington.edu/fsodesignrev/s1genreqsforlabs.pdf

[2] Neuman, V.A. and Sandru, E. (1990) The Advantages of Manifolding Fume Hood Exhausts. ASHRAE Transactions, 96, Part I, 357-360.

[3] Seppänen, O.A., Fisk, W.J. and Mendell, M.J. (1999) Association of Ventilation Rates and $\mathrm{CO} 2$ Concentrations with Health and Other Responses in Commercial and Institutional Buildings. International Journal of Indoor Environment and Health, 9, 226-252.

[4] Jin, M., Memarzadeh, F., Lee, K.S. and Chen, Q. (2012) Experimental Study of Ventilation Performance in Laboratories with Chemical Spills. Building and Environment, 57, 327-335.

[5] Klein, R.C., King, C. and Castagna, P. (2013) Controlling Formaldehyde Exposures in an Academic Gross Anatomy Laboratory. Journal of Occupational and Environmental Hygiene, 11, 127-132.

[6] Sandru, E. (1996) Evaluation of the Laboratory Equipment Component of Cooling Loads. ASHRAE Transactions, 102, Part I, 1278.

[7] Laboratory Ventilation ACH Rates Standards and Guidelines, 23 January 2013, White Paper Series.

http://www.aircuity.com/wp-content/uploads/Aircuity-White-Paper_Lab-Ventilati on-ACH-Rates_Standards-Guidelines_ACHWP_20120103-2.pdf 
[8] Incropera, F.P. and DeWitt, D.P. (2011) Fundamentals of Heat and Mass Transfer. 3rd Edition, John Willey \& Sons, New Jersy, USA.

[9] Lide, D.R. (2003-2004) CRC Handbook of Chemistry and Physics. 84th Edition, CRC Press, Florida, USA

[10] Ratcliff, M.A. and Sandru, E. (1999) Dilution Calculations for Determining Laboratory Exhaust Stack Heights. ASHRAE Transactions Pt. 1, 105, 1-3.

\section{Scientific Research Publishing}

Submit or recommend next manuscript to SCIRP and we will provide best service for you:

Accepting pre-submission inquiries through Email, Facebook, LinkedIn, Twitter, etc. A wide selection of journals (inclusive of 9 subjects, more than 200 journals)

Providing 24-hour high-quality service

User-friendly online submission system

Fair and swift peer-review system

Efficient typesetting and proofreading procedure

Display of the result of downloads and visits, as well as the number of cited articles

Maximum dissemination of your research work

Submit your manuscript at: http://papersubmission.scirp.org/

Or contact aces@scirp.org 